\title{
Superior Mesenteric Artery Syndrome: A Case Report
}

I. Labbi $^{1 *}$, Y. Dkhissi ${ }^{1}$, H. ElBouhaddouti ${ }^{1}$, O. Mouaqit ${ }^{1}$, A. Ousadden ${ }^{1}$, K. AIT Taleb. E. Benjelloun ${ }^{1}$

${ }^{1}$ Department of general surgery A, CHU Hassan II FES, 30000, Morocco

DOI: $\underline{10.36347 / \mathrm{sasjs} .2021 . v 07 i 04.001}$

| Received: 26.02.2021 | Accepted: 03.03.2021 | Published: 02.04.2021

*Corresponding author: I. Labbi

Abstract

Case Report

Introduction: Superior mesenteric artery (SMA) syndrome or Wilkie syndrome is a rare cause of superior bowel obstruction caused by the compression of the third portion of the duodenum during the passage between the superior mesenteric artery and aorta. Clinically, it is characterized by vomiting, nausea and intermittent abdominal pain based on the degree of duodenal compression. Diagnosis is based on abdominal CT scan. First treatment is medical, but frequently surgery is required treatment. Observation: We report a case of superior mesenteric artery syndrome in a male patient aged 21 years with a history of chronic vomiting and weight loss. Abdominal CT scan found a D3stenosis with reduced aorto-mesenteric space related to a mesenteric artery syndrome. The management consisted of surgical treatment after failure of medical treatment with a favorable outcome. Conclusion: The mesenteric artery syndrome is a rare and benign disorder. The abdominal CT scan is of vital interest for the diagnosis in $90 \%$ of cases. Medical treatment is tried first but surgery is common.

Keywords: Superior mesenteric artery syndrome, duodenal occlusion, gastrointestinal anastomosis.

Copyright ( 2021 The Author(s): This is an open-access article distributed under the terms of the Creative Commons Attribution 4.0 International License (CC BY-NC 4.0) which permits unrestricted use, distribution, and reproduction in any medium for non-commercial use provided the original author and source are credited.

\section{INTRODUCTION}

Superior mesenteric artery (SMA) syndrome is a rare cause of upper gastrointestinal obstruction. The defining feature of this syndrome is the compression of the third part of the duodenum between the SMA anteriorly and the aorta posteriorly leading to upper gastrointestinal obstruction.

Several factors can lead to such a syndrome: rapid weight loss (anorexia nervosa, extensive burning, and malabsorption syndrome) decreasing fat mass protecting the duodenum, retro peritoneal hematoma, uterus pregnant or correction of a deformity of the spine by compression cast or by surgery [1].

The most characteristic symptoms of SMA arepost-prandial epigastric fullness with pain, eructation, and bilious vomiting

\section{CASE PRESENTATION}

A twenty-Four-year old male patient was transferred from the gastroenterology department for management of chronic vomiting with weight loss and epigastric pain progressing for then 6 months. Pain localized to the epigastric area with no relieving or aggravating factors. No significant previous surgical or medical problem. Examination revealed very thin patient with normal vitals. Abdominal examination showed mild tenderness with fullness over epigastric area.

The biological impact assessment revealed the presence of ionic disorders: $\mathrm{Na}+$ : $128, \mathrm{k}+$ : 3.2, disturbed nutritional assessment: albuminuria: 27 , total protein: 50, with normal kidney function. The rest of the biological assessment is normal

Patient underwent CT scan abdomen and pelvis that revealed dilated stomach as well as significant reduction of the aorto-mesenteric angle (measuring $11^{\circ}$ ) and aorto-mesenteric distance measuring about $7,8 \mathrm{~mm}$

The management consisted of a medical treatment based on postural treatment in Left lateral decubitus and renutrition by oral then parenteral route for 5 days. In Due to the non-improvement under medical treatment, a surgical diversion (gastro-enteroanastomosis) was performed by laparotomywithout incident). Feeding was resumed on D3postoperative.

\section{DISCUSSION}

First described by Rokitansky in 1861 and then studied in detail by Wilkie in 1921, Superior mesenteric artery syndromeis a rare cause of duodenal obstruction associated with a wide range of predisposing factors [31]. It is caused by extrinsic compression of the third 
portion of the duodenum through the superior mesenteric artery or one of its branches against the aorto-rachidian plane. This obstruction may be partial or complete, acute or chronic, congenital or acquired [64]. The prevalence of aorto-mesenteric clamp syndrome varies between $0.013 \%$ and $0.78 \%$. It occurs preferentially in young patients female. No racial and ethnic predisposition has still been identified [4-6]. Factors favoring the occurrence of this pathology are most often: weight loss rapid resulting in a reduction in the thickness of the fabric adipose in the aortomesenteric space, the correction of scoliosis, spinal hyperlordosis, cerebral palsy and anatomical abnormalities such an enlarged or abnormally short Treitz ligament attracting the third duodenal portion to the top of the duodénojéjunal angle and thus favoring the compression of the digestive segment via the superior mesenteric artery [6,7]. Nevertheless, $40.4 \%$ of cases occur without a factor triggering obvious [6. The symptoms are variable and notspecific.

The installation can be acute or evolve insidiously according to the etiology and the importance duodenal obstruction. The most common clinical signs frequent are abdominal pain, vomiting bilious and nausea, often associated with distension epigastric. They are aggravated by meals and lying down dorsal, relieved by the left lateral decubitus and the seated. This symptomatology poses the problem of diagnosis differential with other pathologies such as pancreatitis, ulcer, and mega duodenum.

The diagnosis, suggested clinically, is confirmed by the abdominal CT angiography which shows a gastroduodenal dilatation up to the level of the third portion of the duodenum with extrinsic compression opposite of the superior mesenteric artery. The distance aorta-superior mesenteric artery is less than $8 \mathrm{~mm}$ (figure 1) and the aorto-mesenteric angle is less than $22^{\circ}$ [12] (figure 2). Support therapy is initially medical aimed at relieving symptoms of the obstruction. She understands decompression gastric by a nasogastric tube, the correction of hydro-electrolyte disturbances. Supplementation nutrition by parenteral or enteral route allows gain weight and restore aorto-mesenteric adipose tissue which, in normal individuals, displaces the superior mesenteric artery in front of the aorta thus avoiding duodenal compression. Hygienic-dietetic measures are fundamental and involve the division of meal, the left lateral decubitus or prone position postprandial [11]. The patient should be monitored narrow and gradual oral feeding should be initiated as soon as symptoms begin to subside [12]. Surgery is indicated in the event of failure of conservative treatment or recurrence. Various interventions were proposed based either on a digestive derivation such a duodeno-jejunal or gastro-jejunal anastomosis, either on the modification of local conditions by section of the Treitz ligament and uncrossing of the duodenojejunal angle by positioning the jejunum to the right of the superior mesenteric artery (Strong's procedure). Nowadays, all these operating methods can be carried out by laparoscopic. Its main advantages are pain less postoperative, a low risk of occlusion on the bridle, an excellent aesthetic result, early recovery of the intestinal peristalsis, and a longer hospital stay short $[11,12]$

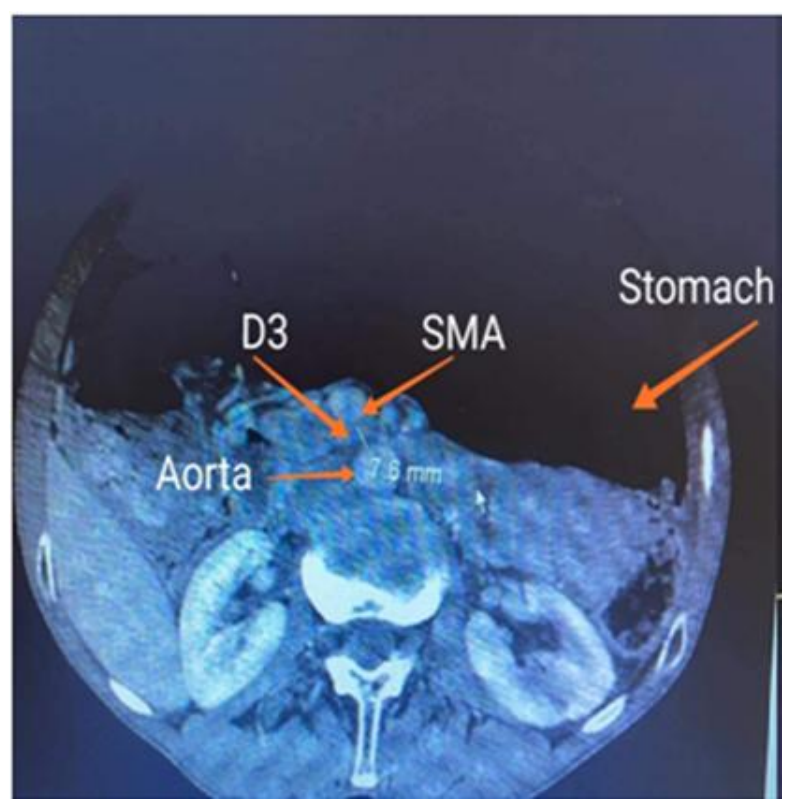

Fig-1: Abdominal CT revealed distension stomach and distance aorta-SMA is $7.8 \mathrm{~mm}$

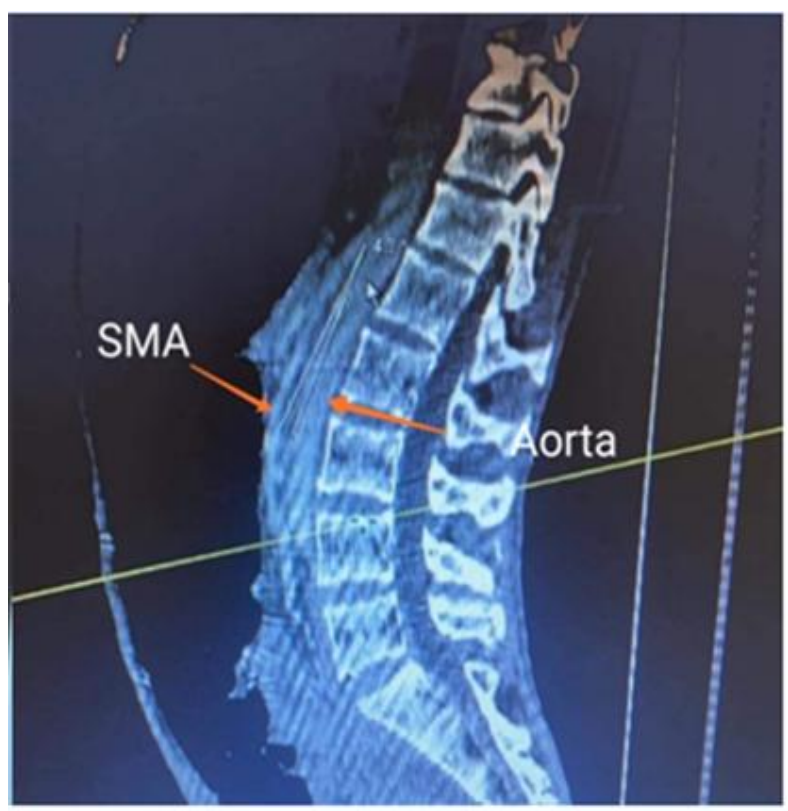

Fig-2: Sagittal CT-slice showing a narrowed aortomesenteric angle

\section{CONCLUSION}

Superior mesenteric artery syndrome is rare cause of intestinal obstruction but should be kept in mind. Persistent vomiting after history of weight loss should raise the suspicious of this diagnosis. Upper GI endoscopy may be necessary to exclude other mechanical causes of duodenal obstruction. Contrast enhanced CT scan is useful in the diagnosis of superior 
mesenteric artery syndrome and can provide diagnostic information. The establishment of appropriate conservative measures and the definition of surgical indications are essential for the prevention complications

\section{Ethical approval} the patient.

Written informed consent was obtained from

\section{Consent} the patient.

Written informed consent was obtained from

\section{Author contributions}

All authors have approved the final article

\section{REFERENCES}

1. Su MC, Lee $\mathrm{CH}$, Wang CC. Education and imaging. Gastrointestinal: superior mesenteric artery syndrome initially presenting like reflux esophagitis. J GastroenterolHepatol. 2010;25:645

2. Cogbill TH, Bintz M, Johnson JA, Strutt PJ. Acute gastric dilatation after trauma. $\mathbf{J}$ Trauma. 1987;27:1113e1117.

3. Singal R, Sahu PK, Goel M, Gupta S, Gupta R, Gupta A etal. Superior mesenteric artery syndrome: a case report.North Am J Med Sci. 2010;2(8):392. PubMed |

4. Mathenge N, Osiro S, Rodriguez II, Salib C, Tubbs RS,Loukas M. Superior mesenteric artery syndrome and itsassociated gastrointestinal implications. ClinAnat N Y N.2014;27(8):12441252. PubMed |
5. Zaraket V, Deeb L. Wilkie's Syndrome or Superior Mesenteric Artery Syndrome: Fact or Fantasy. Case RepGastroenterol. 2015;9(2):194-199. PubMed |

6. Kalouche I, Léturgie C, Tronc F, Bokobza B, Michot F, Pons $\mathrm{P}$ et al. The superior mesenteric artery syndrome: aproposof a case and review of the literature. Ann Chir. 1991;45(7):609-612. PubMed |

7. Bonnet J, Louis D, Foray P. La pinceaortomésentériquesupérieure primitive. Arch Pédiatrie. 1995;2(4):3333- 38

8. Unal B, Aktas A, Kemal G, Bilgili Y, Güliter S, Daphan C et al. Superior mesenteric artery syndrome: CT and ultrasonography findings. DiagnIntervRadiolAnk Turk. 2005;11(2):90-95. PubMed |

9. Chrysikos D, Troupis T, Tsiaoussis J, Sgantzos M, Bonatsos V, Karampelias V et al. Superior mesenteric artery syndrome: a rare case of upper gastrointestinal obstruction. J Surg Case Rep. 2019;2019(3):rjz054. PubMed |

10. So C-Y, Chan K-Y, Au H-Y, Chan M-L, Lai T. Superior mesenteric artery (SMA) syndrome: an unusual cause of intestinal obstruction in palliative care. Ann Palliat Med. 2017;6(1):91-93. PubMed |

11. Mandarry MT, Zhao L, Zhang C, Wei ZQ. A comprehensive review of superior mesenteric artery syndrome. Eur Surg.2010;42(5):229-236.

12. Ganss A, Rampado S, Savarino E, Bardini R. Superior Mesenteric Artery Syndrome: a Prospective Study in a Single Institution. J GastrointestSurg off J SocSurg Aliment Tract. 2019;23(5):997-1005. PubMed I 